\title{
Phases in development of an interactive mobile phone-based system to support self-management of hypertension
}

\author{
Inger Hallberg',1। \\ Charles Taft ${ }^{1,11}$ \\ Agneta Ranerup ${ }^{2,11}$ \\ Ulrika Bengtsson 1,11 \\ Mikael Hoffmann 3,10 \\ Stefan Höfer ${ }^{4}$ \\ Dick Kasperowski ${ }^{5}$ \\ Åsa Mäkitalo ${ }^{6}$ \\ Mona Lundin 6 \\ Lena Ring 7,8 \\ Ulf Rosenqvist ${ }^{9}$ \\ Karin Kjellgren ${ }^{1,10,11}$
}

Institute of Health and Care Sciences,

${ }^{2}$ Department of Applied Information

Technology, University of Gothenburg,

Gothenburg, ${ }^{3}$ The NEPI Foundation,

Linköping, Sweden; ${ }^{4}$ Department of

Medical Psychology, Innsbruck Medical

University, Innsbruck, Austria; ${ }^{5}$ Department

of Philosophy, Linguistics and Theory

of Science, ${ }^{6}$ Department of Education,

Communication and Learning, University

of Gothenburg, Gothenburg, ${ }^{7}$ Centre

for Research Ethics and Bioethics,

Uppsala University, ${ }^{8}$ Department of Use

of Medical Products, Medical Products

Agency, Uppsala, ${ }^{9}$ Department of Medical

Specialist and Department of Medical and

Health Sciences, Linköping University,

Motala, ${ }^{10}$ Department of Medical and

Health Sciences, Linköping University,

Linköping, "Centre for Person-Centred

Care, Sahlgrenska Academy, University of

Gothenburg, Gothenburg, Sweden

Correspondence: Inger Hallberg Institute of Health and Care Sciences, Sahlgrenska Academy, University of Gothenburg, Box 457, SE-405 30,

Gothenburg, Sweden

$\mathrm{Tel}+46317866107$

Fax +46 3I 7866050

Email inger.hallberg@gu.se
This article was published in the following Dove Press journal:

Integrated Blood Pressure Control

7 May 2014

Number of times this article has been viewed

\begin{abstract}
Hypertension is a significant risk factor for heart disease and stroke worldwide. Effective treatment regimens exist; however, treatment adherence rates are poor $(30 \%-50 \%)$. Improving self-management may be a way to increase adherence to treatment. The purpose of this paper is to describe the phases in the development and preliminary evaluation of an interactive mobile phone-based system aimed at supporting patients in self-managing their hypertension. A person-centered and participatory framework emphasizing patient involvement was used. An interdisciplinary group of researchers, patients with hypertension, and health care professionals who were specialized in hypertension care designed and developed a set of questions and motivational messages for use in an interactive mobile phone-based system. Guided by the US Food and Drug Administration framework for the development of patient-reported outcome measures, the development and evaluation process comprised three major development phases (1, defining; 2 , adjusting; 3, confirming the conceptual framework and delivery system) and two evaluation and refinement phases (4, collecting, analyzing, interpreting data; 5 , evaluating the self-management system in clinical practice). Evaluation of new mobile health systems in a structured manner is important to understand how various factors affect the development process from both a technical and human perspective. Forthcoming analyses will evaluate the effectiveness and utility of the mobile phone-based system in supporting the self-management of hypertension.
\end{abstract}

Keywords: adherence, blood pressure, cellular phone, communication, devices, person-centered care

\section{Introduction}

The impact of symptoms on the motivation to follow hypertension treatment regimen has been pointed out in recent research. ${ }^{1}$ For example, symptoms and side effects negatively affecting daily life might - to some degree - explain why poor adherence to treatment is common. Several studies show that only $30 \%-50 \%$ of persons with hypertension follow the treatment prescribed. ${ }^{2,3}$ The impact of this is significant, as hypertension was the largest global risk factor for cardiovascular disease ${ }^{4}$ and mortality in $2010 .^{5}$

Tsiantou et $\mathrm{al}^{6}$ suggest that cognitive and communication factors affect medication adherence. A more personal relationship with the health care professionals and an active role of the patient, as well as previous experience with hypertension, may facilitate adherence to treatment. ${ }^{6}$ Increased interaction and effective communication between health care professionals and the patient may be a way to support self-management of hypertension. ${ }^{7}$ Further, recent reviews ${ }^{1,8}$ conclude that self-monitoring appears to be a useful complement to care and is likely to lead to a reduction in cardiovascular events and mortality. Nundy et $\mathrm{al}^{9}$ suggest that behavioral models should be used to design management programs 
and address health beliefs, self-efficacy, and social support. A recent study by Bokhour et $\mathrm{al}^{10}$ found that patients' ability to perform self-management was affected by their explanatory models, as well as by their daily life experiences. Therefore, innovations including interaction and feedback that focus on the patient's understanding of the interrelationships between blood pressure, symptoms, medications, side effects, lifestyle, and well-being could be ways to support self-management and to motivate persons with hypertension to adhere to lifestyle and medical treatment.

To date, interventions designed to improve adherence to hypertension treatment have not been very successful. Priority should therefore be given to applied research implementing innovative methods to help patients adhere to long-term treatment. ${ }^{11}$ This is partly due to the complex nature and challenges of planning, designing, and performing interventions aimed at improving adherence. ${ }^{12}$ For example, data capture of patient self-reports and their feedback to patients and health care professionals are important aspects to consider in an intervention. ${ }^{13}$

Mobile health (mHealth) has been defined as:

Medical and public health practice supported by mobile devices, such as mobile phones, patient monitoring devices, personal digital assistants, and other wireless devices. ${ }^{14}$

Mobile phones are becoming an important tool for text messaging, patient reports of daily activities, symptoms, and adherence to treatment. ${ }^{15-19}$ Although mobile phone technology is used in a wide variety of health care settings, there are few research studies that describe the development process of mobile phone-based interventions for disease management and health monitoring. ${ }^{20}$

There is, therefore, a need to develop innovative and effective strategies that derive from and integrate patients' and professionals' perspectives to improve adherence to both medication and lifestyle changes. A person-centered perspective ${ }^{21}$ may be helpful in guiding such efforts. The overall aim of the ongoing research program is to develop and evaluate the feasibility, effectiveness, and utility of an interactive mobile phonebased system aimed at supporting patients in self-managing hypertension. The purpose of this paper is to describe the phases in the development of the system and to report preliminary results from the initial clinical evaluations.

\section{Methods}

The research program was developed by an interdisciplinary group of researchers and has a participatory orientation, which involves persons with hypertension and health care professionals working together in the development process. ${ }^{22}$ Therefore, the development and evaluation process was guided by the recommendations outlined in the US Food and Drug Administration's patient-reported outcome measures guidance. ${ }^{23}$ This framework was assessed as suitable for use with the participatory design. A communication system for mobile phones (with platforms, such as Java Micro Edition, iOS, Android, and [from 2013] also Windows Phone), Circadian Questions (CQ), developed by 21st Century Mobile, Stockholm, Sweden, (http://www.cqmobil.se), was adapted for use in this study.

\section{Ethics}

The project was approved by the Regional Ethics Board in Gothenburg, Sweden (study code 551-09 and T-100-12). The patients and professionals were given both written and oral information that their participation was voluntary and that their responses would be kept confidential and would only be presented as anonymous excerpts or quotes in scientific publications. The project was planned and is being conducted in accordance with the Declaration of Helsinki. ${ }^{24}$ Phases 4 and 5 were given the acronym MIHM (Mobile phone In Hypertension Management) and were registered in the Clinical Trial Protocol Registration System. ${ }^{25}$ The study was monitored by an independent monitoring board to ensure that the data were entered accurately.

\section{Results}

Together, with an interdisciplinary group of researchers, patients with hypertension and health care professionals specialized in hypertension care designed and developed an initial set of questions and motivational messages for use in a prototype interactive mobile phone-based delivery system. The research program is comprised of five phases based on the methods summarized in Table 1. The phases: 1) define conceptual framework and delivery system; 2) adjust conceptual framework; 3) confirm conceptual framework and delivery system; 4) collect, analyze, and interpret data; and 5) evaluate the self-management support system in clinical practice. This paper summarizes phases $1-5$. For a flowchart of the research program, see Figure 1. Analysis of the research program is currently underway, and analyses of outcome data will take place in 2014.

\section{Phase I: define conceptual framework and delivery system}

The aim of phase 1 was to draft a conceptual framework for the prototype mobile phone system aimed at supporting 
Table I Overview of phases, aims, design, participants, methods, and analyses in the development process of an interactive mobile phone-based system to support self-management of hypertension

\begin{tabular}{|c|c|c|c|c|c|}
\hline & $\begin{array}{l}\text { Phase I } \\
\text { Define conceptual } \\
\text { framework, } \\
\text { delivery system }\end{array}$ & $\begin{array}{l}\text { Phase } 2 \\
\text { Adjust conceptual } \\
\text { framework }\end{array}$ & $\begin{array}{l}\text { Phase } 3 \\
\text { Confirm conceptual } \\
\text { framework, delivery } \\
\text { system }\end{array}$ & $\begin{array}{l}\text { Phase } 4 \\
\text { Collect, analyze, } \\
\text { interpret data }\end{array}$ & $\begin{array}{l}\text { Phase } 5 \\
\text { Evaluate } \\
\text { self-management } \\
\text { support system } \\
\text { in clinical practice }\end{array}$ \\
\hline Aims & $\begin{array}{l}\text { To draft conceptual } \\
\text { framework } \\
\text { for prototype mobile } \\
\text { phone system }\end{array}$ & $\begin{array}{l}\text { To evaluate compiled } \\
\text { concepts and } \\
\text { complement them with } \\
\text { other relevant aspects } \\
\text { of hypertension }\end{array}$ & $\begin{array}{l}\text { To examine } \\
\text { comprehension, } \\
\text { comprehensiveness, } \\
\text { relevance of items, and } \\
\text { to examine its usability }\end{array}$ & $\begin{array}{l}\text { To evaluate patient } \\
\text { self-report data, } \\
\text { experiences of using } \\
\text { self-management } \\
\text { support system }\end{array}$ & $\begin{array}{l}\text { To evaluate } \\
\text { understanding, } \\
\text { interaction, } \\
\text { participating in care }\end{array}$ \\
\hline Design & Explorative & $\begin{array}{l}\text { Qualitative, } \\
\text { interpretive }\end{array}$ & Design, pilot testing & $\begin{array}{l}\text { Qualitative, quantitative, } \\
\text { before-after design }\end{array}$ & $\begin{array}{l}\text { Qualitative, } \\
\text { interpretive }\end{array}$ \\
\hline Participants & $\begin{array}{l}\text { Researchers from } \\
\text { interdisciplinary group } \\
(n=7) \text {; technical experts } \\
\text { on developing mobile } \\
\text { phone system }(n=3)\end{array}$ & $\begin{array}{l}\text { Patients }(n=15) ; \\
\text { professionals }(n=12)\end{array}$ & $\begin{array}{l}\text { Patients }(n=21) \\
\text { professionals }(n=4)\end{array}$ & $\begin{array}{l}\text { Patients }(n=50) \\
\text { professionals }(n=8)\end{array}$ & $\begin{array}{l}\text { Patients and } \\
\text { professionals in audio } \\
(\mathrm{n}=10) \text { and video } \\
(\mathrm{n}=10) \text { recorded } \\
\text { consultations }\end{array}$ \\
\hline Methods & $\begin{array}{l}\text { Literature search, } \\
\text { experience } \\
\text { of evidence-based } \\
\text { practice }\end{array}$ & Focus groups & Cognitive interviews & $\begin{array}{l}\text { Mobile phone } \\
\text { self-report questions, } \\
\text { semistructured } \\
\text { interviews }\end{array}$ & $\begin{array}{l}\text { Audio/video } \\
\text { recording, } \\
\text { semistructured } \\
\text { interviews }\end{array}$ \\
\hline Analyses & Descriptive & Thematic analysis & $\begin{array}{l}\text { Structured iterative } \\
\text { analysis; item-tracking } \\
\text { matrix }\end{array}$ & $\begin{array}{l}\text { Descriptive, analytical } \\
\text { statistics; thematic } \\
\text { analysis }\end{array}$ & Interaction analysis \\
\hline
\end{tabular}

self-management of hypertension and to explore possible uses of the mobile phone system in clinical practice.

\section{Procedure}

Our point of departure was person-centeredness. Central to person-centered care ${ }^{26}$ is that the patient be given the opportunity and support to actively participate and be engaged in planning and decision-making regarding his or her care and treatment. There is evidence that patients report better outcomes and satisfaction with their care when they are actively involved and receive effective treatments, self-management support, and regular follow-up in coordinated systems. ${ }^{21,27}$ The Common Sense Model was used to guide the development of the self-management system, ${ }^{28-30}$ which implies that actions taken to reduce health risks are guided by the patient's subjective or common sense

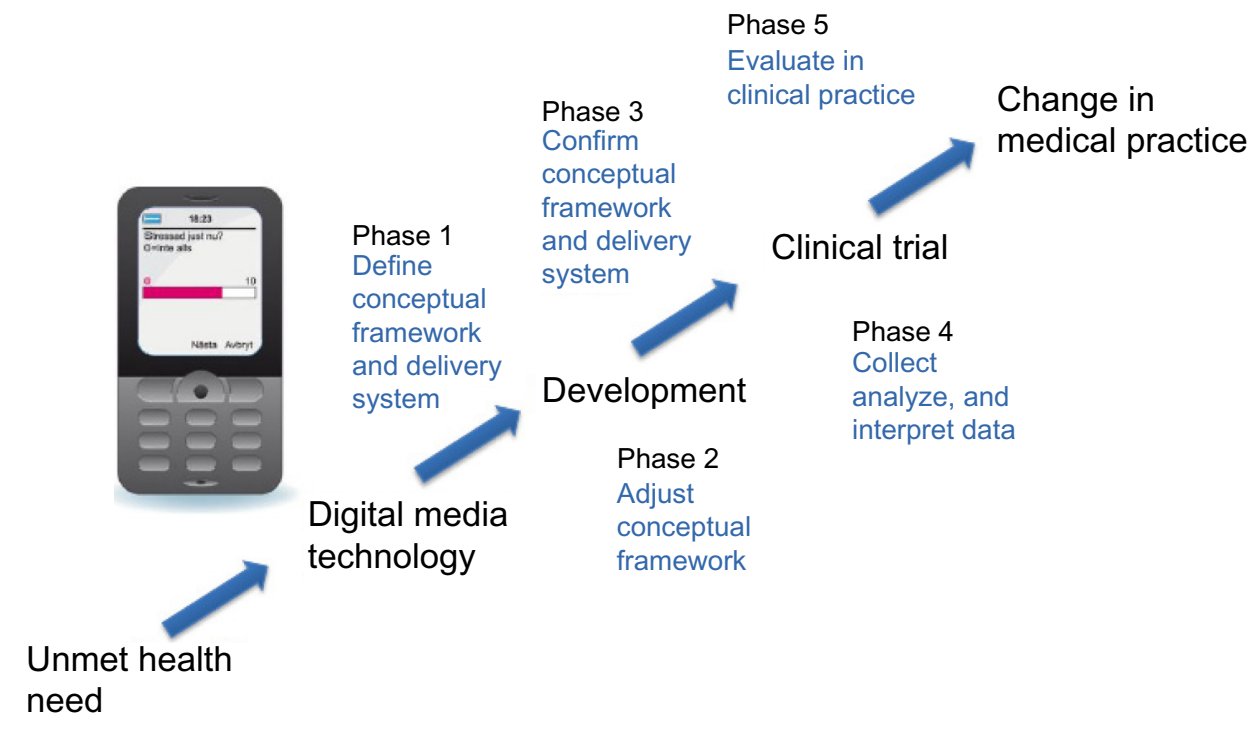

Figure I Flowchart of the research program. 
perceptions of the health threat. This behavior model can help researchers and professionals understand patients' perceptions of illness and coping strategies as it focuses on the patients' beliefs about the health problem, condition, or recommended actions.

A literature search ${ }^{31-34}$ was conducted to compile potentially relevant concepts for hypertension self-management regarding symptoms of hypertension and its treatment, clinical measurements, and examples of lifestyle habits. Additional concepts were derived from a Swedish national multicenter study ${ }^{35}$ Motivational messages and reminders were also proposed. During this phase, seven researchers and three technical experts met at regularly scheduled meetings to discuss these issues.

The mobile phone self-report delivery and data capture system by CQ is designed such that self-reports are registered by means of the patients' own mobile phones and are returned to and stored in a database, with levels of security comparable to those used within Internet banking systems. For the purposes of this study, the CQ system was further adapted and refined so that patients could receive feedback in the form of login-restricted access to web-based structured graphical presentations of their self-reported blood pressure, side effects, symptoms, and well-being in relation to their drug intake and lifestyle. Additionally, attending physicians/nurses were enabled access to this data for use in patient consultations. The graphs were expected to serve as a tool to help patients visualize how drug intake/lifestyle relates to blood pressure, symptom relief, and well-being, and - ultimately - helping to improve patient adherence to treatment for hypertension. The feedback system was also anticipated to facilitate and support patient-provider (physician/nurse) interactions. Interactivity was defined: "as the degree to which a communication technology [...] can communicate [...], both synchronously and asynchronously, and participate in reciprocal message exchanges." 36

\section{Outcome from phase I}

A list of predefined concepts (ie, symptoms), clinical measurements, and examples of lifestyle habits was compiled to be tested in the next phase. This list is available upon request from the authors. Optional motivational messages and reminders were added to motivate the patients to follow the regimen agreed upon. A prototype of questions and motivational messages to be used in the mobile phone-based system was constructed. The mobile phone system was adapted and refined to meet the needs of the study.

\section{Phase 2: adjust conceptual framework}

The aims of phase 2 were to evaluate the compiled concepts and complement them with other relevant aspects of hypertension and its treatment, eg, clinical measures, lifestyle measures, symptoms, and side effects that patients and professionals considered important for supporting selfmanagement.

\section{Procedure}

Three focus group interviews were performed with 15 patients and two with 12 professionals (physicians, nurses, and pharmacists) from a primary health care center and an outpatient medical clinic in Sweden. The focus group interviews were transcribed verbatim. The interviews were analyzed by means of thematic analysis. ${ }^{37}$ The thematic analysis was conducted by two of the coauthors. Both had long experience in using this method. Inclusion criteria for patients were $>30$ years of age and currently taking drugs for hypertension. The health care professionals had to have experience of caring for patients with hypertension. Two interview guides, one for the patient group and one for the health care professional group, were used.

Examples of questions to the patients were: "Do you have any symptoms?"; "What inconvenience do you experience?"; and "What do you need to better manage your hypertension?"

Examples of questions to health care professionals were: "What are the aims of the pharmacological treatment?"; "Do patients share these aims?"; and "How do you motivate patients to adhere to the treatment regimen?"

A list of predefined symptoms, clinical measurements, and examples of lifestyle habits, were given to the patients and professionals, and they were asked to number these according to priority of perceived importance to follow-up.

\section{Outcome from phase 2}

Symptoms, measurements, and habits that patients and health care professionals believed were important to assess were identified and defined..$^{38}$ This information formed the basic framework for concepts and issues to be included in the mobile phone-based system.

\section{Phase 3: confirm conceptual framework and delivery system}

The aims of phase 3 were to confirm the conceptual framework, specifically to examine the comprehension, comprehensiveness, and relevance of the items, and to examine the usability of the mobile phone system. 


\section{Procedures}

Based on results from phase 2, a draft set of questions was developed and adapted to the constraints imposed by mobile phone screen presentation. In this phase, content validity and usability were ensured by performing the rounds of cognitive interviews ${ }^{39}$ with 21 patients and four health care professionals selected using the same inclusion criteria as in phase 2 . The analysis was based on an item tracking matrix. ${ }^{40}$

The interactive technology ${ }^{36}$ consisted of: A) a mobile phone system for delivery and capture of patient self-reports and optional motivational messages and reminders; B) a blood pressure monitor (BP A200 AFIB; Microlife USA, Inc., Clearwater, FL, USA) validated according to the international protocol of the European Society of Hypertension; ${ }^{41}$ C) a database for storing daily patient self-reports; and D) a web-based platform for visualization of patient-reported data (Figure 2). The patients were individually trained to use the mobile phone system and to measure their blood pressure using the blood pressure monitor. Reliability of the mobile phone self-report questions was examined using a test-retest protocol.

\section{Outcome from phase 3}

The usability, reliability, and understanding of the developed items were tested. Items that were difficult to understand were modified. The self-report system resulted in a set of questions to be asked daily. The questions were related to well-being, symptoms, lifestyle, medication intake, side effects, and blood pressure (Figure 2). A plan for pilot testing the system for 12 weeks was developed. Usability of the mobile phone-based system and blood pressure device was verified.

\section{Phase 4: collect, analyze, and interpret data}

The aims of phase 4 were to evaluate patient self-report data and the patients' and professionals' experiences of using the interactive mobile phone-based self-management system. Analyses in this and the subsequent phase are currently underway.

\section{Procedures}

Inclusion criteria were the same as during phase 3, with the following additions: 1) access to a mobile phone with Internet access; and 2) consent from prospective patients to access their data at the National Prescription Repository to confirm medication use. ${ }^{42}$ After results from phases $1-3$ were analyzed, the design of the mobile phone self-management system was prepilot tested by two patients for 12 weeks and subsequently tested in an adequately powered 8-week clinical pilot study with 51 patients.

Self-reports by the patients will be further analyzed with a focus on blood pressure, symptoms, medications, adherence, side effects, lifestyle, and well-being. Further, patient evaluations of the motivational messages and reminders will be analyzed. Audio-recorded follow-up interviews with patients and professionals regarding the experiences of the self-management support system, focusing on the

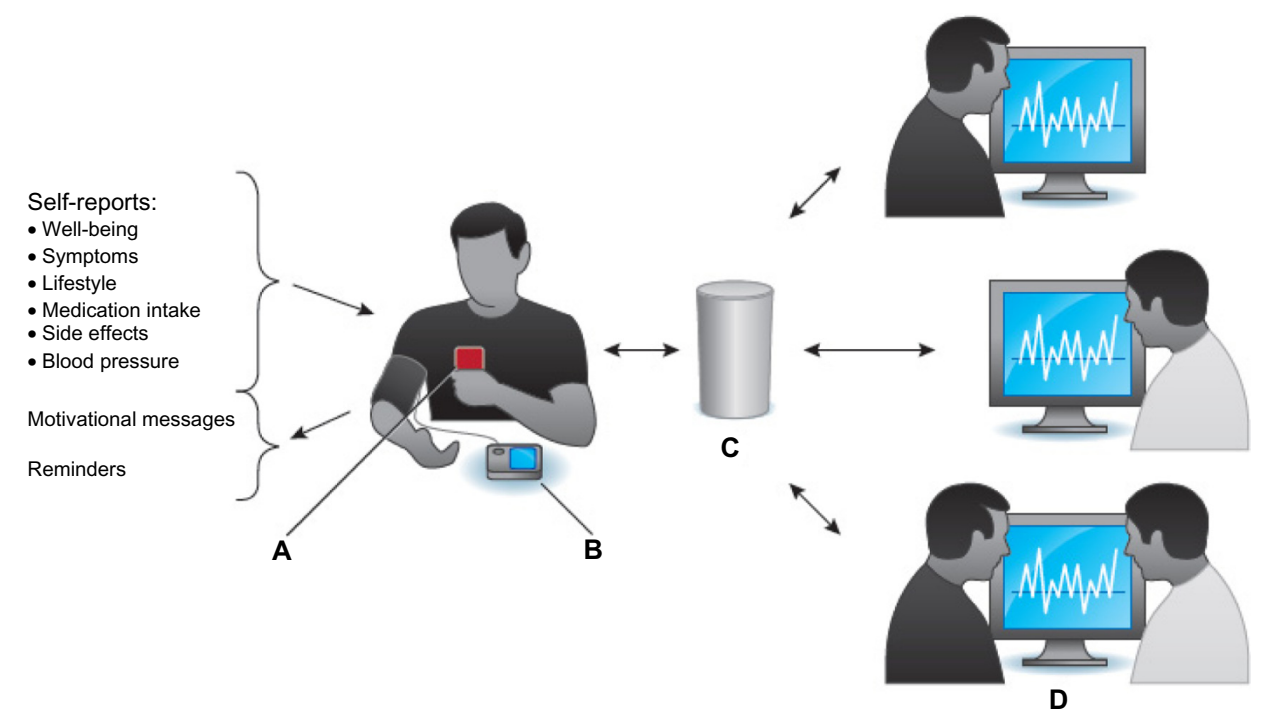

Figure 2 Overview of the interactive self-management support system.

Notes: The system consists of: (A) mobile phone-based system for the self-report questions, together with optional motivational messages and reminders; (B) blood pressure device; (C) database for real-time registration of the daily self-reports captured from the mobile phone; and (D) web-based platform for real-time visualization of the patients' reported data, available after log-in for the patient and physician/nurse and, for example, at consultations. 
assessment of feasibility of the self-management system, were conducted after 4 weeks and after 8 weeks. Qualitative thematic analysis ${ }^{37}$ will be used to identify and analyze patterns or themes.

\section{Outcome from phase 4}

In addition, 50 of 51 patients completed the 8-week study. Preliminary analyses showed that both patients and health care professionals considered the system to be usable and useful. Many patients reported that the web-based graphical feedback of self-reported medication intake, symptoms, physical activity, and well-being in relation to blood pressure helped them to gain insight into the importance of following the treatment regimen (Figures 3 and 4); however, some of the patients pointed out that the graphs were difficult to interpret and suggested the need to simplify them.

\section{Phase 5: evaluate self-management support system in clinical practice}

The aims of phase 5 were to evaluate and analyze whether an interactive mobile phone self-management support system can facilitate and improve: 1) the patients' understanding of the importance of adhering to treatment; and 2) the patientphysician/nurse interactions and patient participation in care. Analyses in this phase are currently being conducted.

\section{Procedures}

Inclusion criteria were the same as in phase 4. Patients received feedback in the form of secure web-based graphical presentations of their daily self-reported blood pressure, side effects, symptoms, and well-being in relation to their drug intake. Additionally, attending professionals also had an immediate login-restricted access to the data for use during, for example, patient consultations and counseling. The graphs were intended as a tool to help patients visualize how drug intake relates to blood pressure, symptom relief, and well-being, and - ultimately - as an aid to improving patient adherence to treatment (Figure 4). Ten patient-physician/nurse consultations were audio-recorded; ten were video-recorded to document and evaluate the use of the self-management system in follow-up consultations. The recordings will be transcribed and analyzed by means of interaction analysis ${ }^{43}$ to explore the structure and the content of the interaction between patient and professional.

\section{Outcome from phase 5}

Analyses of the patient-physician/nurse consultations are currently being conducted. A central research question is if and how the system influences and transforms such consultations, particularly with respect to traditional patient-provider roles, responsibilities, participation levels, etc, within a framework for person-centered care. ${ }^{21,27}$ The length of the conversation, discourse space, words, and the initiation of topics - as well as the risk factors addressed in the consultations - will be explored. Specific questions to be addressed include: "How does the mobile phone-based system mediate communication between health care professionals and patients?"; "What problems become topical and how are these dealt with?"; and "What conditions are decisive for the individual's learning, ie, the process of becoming more independent and successful in managing hypertension?"

\section{Discussion}

This paper summarizes the development and preliminary evaluation of an interactive self-management support system for hypertension comprising a set of questions and motivational messages delivered and captured by means of mobile phone-based technology. The system comprises a module for the delivery and capture of patient reports of well-being, symptoms, lifestyle, medication intake, and blood pressure by means of mobile phone-based technology, tailored phonebased motivational messages, and reminders. Preliminary analyses indicate that the system is indeed useful to and intuitively usable by patients in self-managing their hypertension.

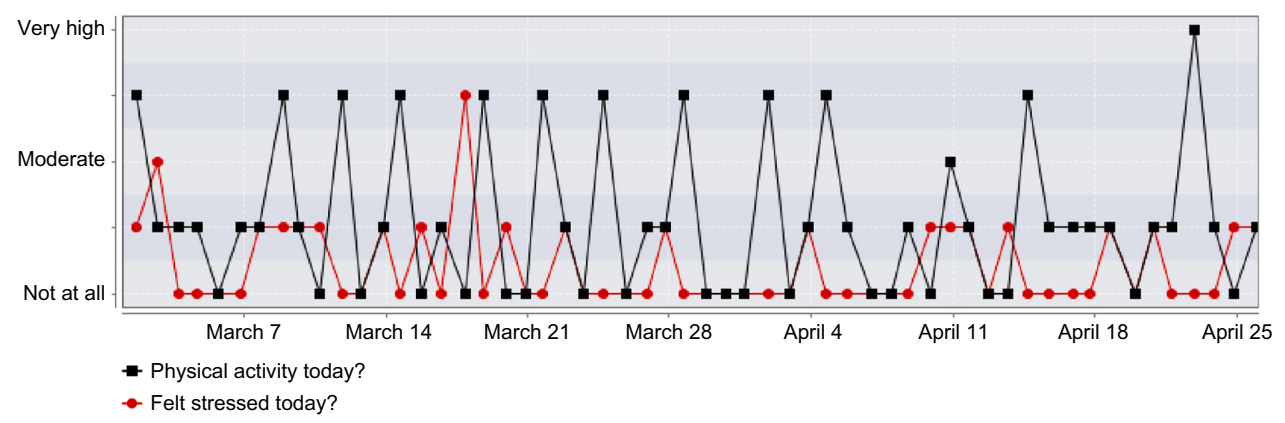

Figure 3 Graph shows combined responses to daily physical activity and perceived levels of stress over 8-week period. 


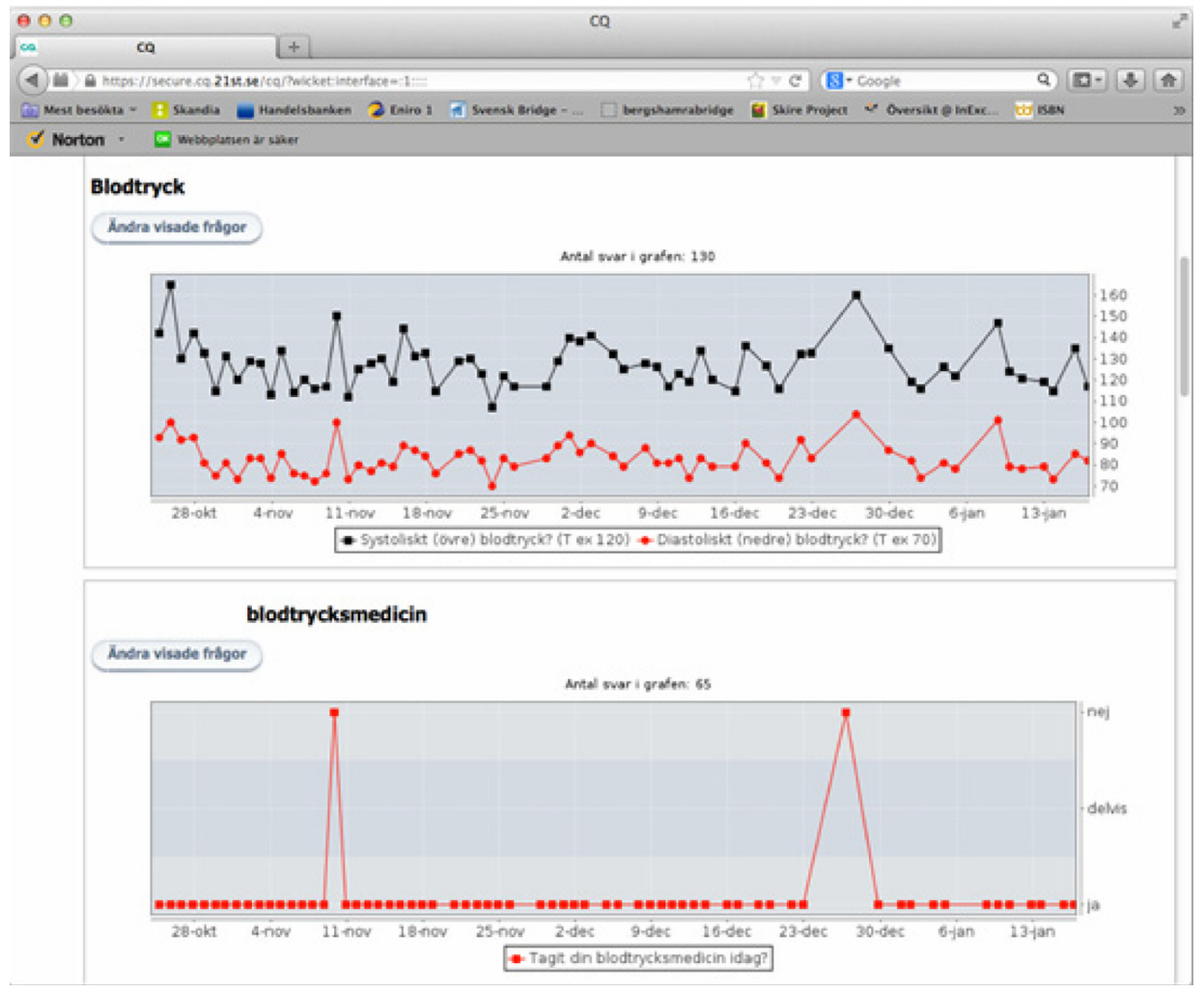

Figure 4 Screenshot from the web-based platform (prepilot study of 12 weeks).

Notes: Upper graphs show blood pressure. Systolic (black squares) and diastolic (red dots). Bottom graph shows drug intake (red squares). A distinct rise in blood pressure can be seen when the patient did not take the antihypertensive drug The communication system for mobile phones Circadian Questions (CQ) was used (http://www.camobil.se).

In this study the patient's own mobile phone was used and this probably facilitated the use of the self-management system in everyday life. Patients, health care professionals, technical experts, and an interdisciplinary group of researchers were involved in the development and evaluation process to enhance the utility and functionality of the system. ${ }^{44}$

Our research program endeavors to develop and to evaluate a tool to empower patients in self-managing their hypertension and in their interactions with health care professionals. Mobile phones and blood pressure devices are widely available and are practical, low-cost tools that may facilitate and support patient empowerment and involvement in their management of hypertension. There is convincing evidence that home blood pressure measurements provide more reliable values and are better predictors of cardiovascular complications than clinic-based measurements. ${ }^{45,46}$ Feedback from our system, in the form of graphs of reported symptom experiences, blood pressure, etc, in relation to one another, may serve to promote understanding of the interplay between symptoms, exercise, medication intake, and blood pressure and to support health care consultations. ${ }^{47}$

Indeed, mHealth solutions developed from an interdisciplinary perspective have the potential to improve counseling and, thereby, motivate patients to adhere to treatment, and thus make better use of health care resources. ${ }^{48}$ However, a major challenge for health care lies in transforming traditional paternalistic patient-physician/nurse relationships such that the patient may take a more active and equal role in planning and decision making regarding his/her care and treatment, in line with person-centered approaches. ${ }^{21}$ The importance of this integrated approach to hypertension management for adherence to treatment has previously been emphasized ${ }^{49}$ and identified as a key factor for effective communication in hypertension care.

The rapid growth in the use of mobile platforms to report health status, driven both by the medical technology industry and patient groups (such as Quantified Self), stands in contrast to the rigorous and demanding process of evaluating their use in clinical practice. ${ }^{50}$ It is important to distinguish between endeavors to develop solutions appropriate for patients with specific characteristics and more demanding endeavors to develop and test more generic solutions applicable in wider patient groups, including the assessment of how these solutions might influence the patient-physician relationship. The time required to develop an mHealth intervention may be as long as 3 to 4 years. ${ }^{20}$ This time is particularly long 
considering that the technology itself continues to evolve quickly and people's use of the technology is continually changing. Nonetheless, evaluation of new technologies in a structured manner is important to understand how various factors affect the development process from both a technical and human perspective.

Relying heavily on the principles of participatory design, the system is unique in that its various components stem principally from the patients themselves about what they need to more effectively self-manage their high blood pressure, as well as on the clinicians' views of their clinical relevance. Hence, our point of departure was that the system should be: 1) clearly useful to patients in managing their hypertension; and 2) relevant for clinical practice. Another guiding principle in developing the system was that it should be easy to use and to rely on readily available and, for the patient, familiar technology, vis-à-vis his/ her own mobile phone. Hence, a major challenge was to produce a system that would function even on small mobile phone displays.

A limitation of participatory design approaches, as in this study, is that they are often associated with selection bias; for example, often the responsive patients who already adhere to treatment are included and nonadherent patients for whom the intervention is potentially most beneficial are often excluded. Another limitation is that patients and health care professionals may find it difficult to evaluate a technology system that they are unfamiliar with. This was evident in phase 2 of our study, but in phases 3 and 4, they had received training with and had a chance to familiarize themselves with the system.

The mHealth is a relatively new field and little is still known about how to best develop and evaluate new technologies to be used in clinical practice. ${ }^{20}$ The impact of increased patient awareness of hypertension and new treatment technologies has been pointed out in several new guidelines for the treatment of hypertension. According to the National Health and Nutrition Evaluation Survey in 2007-2010, only $81.5 \%$ of those with hypertension are aware of their condition, $74.9 \%$ are being treated, and only $52.5 \%$ are under control, with significant variation across different subgroups. ${ }^{51}$ There are many systems for follow-up, such as short text messaging, symptom monitoring, and reminders as a means of interaction with users. ${ }^{52-54}$

Interaction between the patient and the health care professional may be a key issue when developing a self-management system. The active involvement by the patient, regardless of the technology, is of special importance in primary care and for follow-up of long-term conditions..$^{51,55}$ It is necessary to document development processes and outcomes from mHealth interventions so that we can continue to learn and improve our knowledge base about useful interventions in clinical practice.

\section{Conclusion}

Our research program endeavors to develop and evaluate an interactive mobile phone system to support selfmanagement of hypertension by enabling patients to gain a first-hand understanding of how their medication intake and lifestyle affects blood pressure and well-being. Applying a participatory approach that involves patients, health care professionals, and technical experts when developing and designing the system appears to have resulted in a system that patients find very useful for self-management of hypertension. Evaluation of new mHealth systems in a structured manner is important to understand how various factors affect the development process from both the technical and the human perspective. Forthcoming analyses will evaluate the effectiveness and utility of the mobile phone-based system in supporting self-management, in facilitating patient participation, and in communication with physicians and nurses.

\section{Acknowledgments}

We are indebted to the patients, professionals, and experts for their contributions to this research. The research reported here has been financed by and conducted within the University of Gothenburg Learning and Media Technology Studio, in collaboration with the University of Gothenburg Centre for Person-Centred Care in Sweden. The Learning and Media Technology Studio is a strategic initiative for promoting interdisciplinary research within the learning sciences at the University of Gothenburg that addresses issues of knowledge, learning, communication, and expertise in contemporary society. The University of Gothenburg Centre for PersonCentred Care is funded by the Swedish government's strategic investment in health and care (application to the Swedish Research Council number 2009-1088) and cofunded by the University of Gothenburg, Gothenburg, Sweden.

\section{Disclosure}

The opinions or assertions in this article are the views of the authors and are not to be construed as official or as reflecting the views of the Medical Products Agency, Uppsala, 
Sweden. The authors report no other conflicts of interest in this work.

\section{References}

1. Marshall IJ, Wolfe CD, McKevitt C. Lay perspectives on hypertension and drug adherence: systematic review of qualitative research. BMJ. 2012;345:e3953.

2. Sabaté E, editor. Adherence to Long-Term Therapies: Evidence for Action. Geneva, Switzerland: World Health Organization; 2003. Available from: http://www.who.int/chp/knowledge/publications/adherence_report/en/index.html. Accessed April 2, 2014.

3. Egan BM, Zhao Y, Axon RN. US trends in prevalence, awareness, treatment, and control of hypertension, 1988-2008. JAMA. 2010;303(20): 2043-2050.

4. Lim SS, Vos T, Flaxman AD, et al. A comparative risk assessment of burden of disease and injury attributable to 67 risk factors and risk factor clusters in 21 regions, 1990-2010: a systematic analysis for the Global Burden of Disease Study 2010. Lancet. 2012;380(9859):2224-2260.

5. Lozano R, Naghavi M, Foreman K, et al. Global and regional mortality from 235 causes of death for 20 age groups in 1990 and 2010: a systematic analysis for the Global Burden of Disease Study 2010. Lancet 2012;380(9859):2095-2128.

6. Tsiantou V, Pantzou P, Pavi E, Koulierakis G, Kyriopoulos J. Factors affecting adherence to antihypertensive medication in Greece: results from a qualitative study. Patient Prefer Adherence. 2010;4:335-343.

7. Jolles EP, Clark AM, Braam B. Getting the message across: opportunities and obstacles in effective communication in hypertension care. J Hypertens. 2012;30(8):1500-1510.

8. Glynn LG, Murphy AW, Smith SM, Schroeder K, Fahey T. Interventions used to improve control of blood pressure in patients with hypertension [review]. Cochrane Database Syst Rev. 2010;3:CD005182.

9. Nundy S, Dick JJ, Solomon MC, Peek ME. Developing a behavioral model for mobile phone-based diabetes interventions. Patient Educ Couns. 2013;90(1):125-132.

10. Bokhour BG, Cohn ES, Cortés DE, et al. The role of patients' explanatory models and daily-lived experience in hypertension self-management. J Gen Intern Med. 2012;27(12):1626-1634.

11. Haynes RB, Ackloo E, Sahota N, McDonald Heather P, Yao X. Interventions for enhancing medication adherence [review]. Cochrane Database Syst Rev. 2008;2:CD000011.

12. Craig P, Dieppe P, Macintyre S, Michie S, Nazareth I, Petticrew M; Medical Research Council Guidance. Developing and evaluating complex interventions: the new Medical Research Council guidance. BMJ. 2008;337:a1655.

13. Bosworth HB, Olsen MK, Neary A, et al. Take Control of Your Blood Pressure (TCYB) study: a multifactorial tailored behavioral and educational intervention for achieving blood pressure control. Patient Educ Couns. 2008;70(3):338-347.

14. World Health Organization. mHealth: New Horizons for Health through Mobile Technologies. Second Global Survey on eHealth. Global Observatory for eHealth Series. Volume 3. Geneva, Switzerland: World Health Organization; 2011.

15. Vodopivec-Jamsek V, de Jongh T, Gurol-Urganci I, Atun R, Car J. Mobile phone messaging for preventive health care [review]. Cochrane Database Syst Rev. 2012;12:CD007457.

16. Li LC, Townsend AF, Badley EM. Self-management interventions in the digital age: new approaches to support people with rheumatologic conditions. Best Pract Res Clin Rheumatol. 2012;26(3):321-333.

17. de Jongh T, Gurol-Urganci I, Vodopivec-Jamsek V, Car J, Atun R. Mobile phone messaging for facilitating self-management of longterm illnesses [review]. Cochrane Database Syst Rev. 2012;12: CD007459.

18. Blake H. Mobile phone technology in chronic disease management. Nurs Stand. 2008;23(12):43-46.
19. Logan AG. Transforming hypertension management using mobile health technology for telemonitoring and self-care support. Can J Cardiol. 2013;29(5):579-585.

20. Whittaker R, Merry S, Dorey E, Maddison R. A development and evaluation process for $\mathrm{mHealth}$ interventions: examples from New Zealand. J Health Commun. 2012;17 Suppl 1:11-21.

21. Ekman I, Swedberg K, Taft C, et al. Person-centered care - ready for prime time. Eur J Cardiovasc Nurs. 2011;10(4):248-251.

22. Spinuzzi C. The methodology of participatory design. Technical Communication. 2005;52(2):163-174.

23. US Department of Health and Human Services, Food and Drug Administration. Guidance for Industry: Patient-Reported Outcome Measures: Use in Medical Product Development to Support Labeling Claims. Rockville, MD, USA: Food and Drug Administration; 2009. Available from: http://www.ispor.org/workpaper/FDA\%20PRO $\% 20$ Guidance.pdf. Accessed April 2, 2014.

24. World Medical Association Inc. Declaration of Helsinki, Ethical Principles for Medical Research Involving Human Subjects. Ferney-Voltaire, France; 2008. Available from: http://www.wma. net/en/30publications/10policies/b3/index.html. Accessed April 2, 2014.

25. Göteborg University. Mobile Phone in Hypertension Management. Available from: http://clinicaltrials.gov/show/NCT01510301. NLM identifier: NCT01510301. Accessed March 26, 2014.

26. Mead N, Bower P. Measuring patient-centredness: a comparison of three observation-based instruments. Patient Educ Couns. 2000;39(1): 71-80.

27. Leplege A, Gzil F, Cammelli M, Lefeve C, Pachoud B, Ville I. Person-centredness: conceptual and historical perspectives. Disabil Rehabil. 2007;29(20-21):1555-1565.

28. Kucukarslan SN. A review of published studies of patients' illness perceptions and medication adherence: lessons learned and future directions. Res Social Adm Pharm. 2012;8(5):371-382.

29. Leventhal H, Leventhal EA, Breland JY. Cognitive science speaks to the "common-sense" of chronic illness management. Ann Behav Med. 2011;41(2):152-163.

30. Meyer D, Leventhal H, Gutmann M. Common-sense models of illness: the example of hypertension. Health Psychol. 1985;4(2): 115-135.

31. Erickson SR, Williams BC, Gruppen LD. Perceived symptoms and health-related quality of life reported by uncomplicated hypertensive patients compared to normal controls. J Hum Hypertens. 2001;15(8): 539-548.

32. Benson J, Britten N. What effects do patients feel from their antihypertensive tablets and how do they react to them? Qualitative analysis of interviews with patients. Fam Pract. 2006;23(1):80-87.

33. Svensson S, Kjellgren KI. Adverse events and patients' perceptions of antihypertensive drug effectiveness. J Hum Hypertens. 2003;17(10): 671-675.

34. Middeke M, Lemmer B, Schaaf B, Eckes L. Prevalence of hypertensionattributed symptoms in routine clinical practice: a general practitionersbased study. J Hum Hypertens. 2008;22(4):252-258.

35. Kjellgren KI, Ahlner J, Dahlöf B, Gill H, Hedner T, Säljö R. Perceived symptoms amongst hypertensive patients in routine clinical practice - a population-based study. J Intern Med. 1998;244(4): 325-332.

36. Kiousis S. Interactivity: a concept explication. New Media and Society. 2002;4(3):355-383.

37. Braun V, Clarke V. Using thematic analysis in psychology. Qual Res Psychol. 2006;3(2):77-101.

38. Bengtsson U, Kasperowski D, Ring L, Kjellgren K. Developing an interactive mobile phone self-report system for self-management of hypertension. Part 1: Patient and professional perspectives. Blood Press. Epub February 24, 2014.

39. Beatty PC, Willis GB. Research Synthesis: The Practice of Cognitive Interviewing. Public Opin Q. 2007;71(2):287-311. 
40. Patrick DL, Burke LB, Gwaltney CJ, et al. Content validity - establishing and reporting the evidence in newly developed patient-reported outcomes (PRO) instruments for medical product evaluation: ISPOR PRO Good Research Practices Task Force report: part 2 - assessing respondent understanding. Value Health. 2011;14(8):978-988.

41. O'Brien E, Atkins N, Stergiou G, et al; Working Group on Blood Pressure Monitoring of the European Society of Hypertension. European Society of Hypertension International Protocol revision 2010 for the validation of blood pressure measuring devices in adults. Blood Press Monit. 2010;15(1):23-38.

42. Ekedahl A, Hoffmann M. Patients' information on their prescribed current treatment. J Pharm Health Serv Res. 2012;3(2):79-84.

43. Jordan B, Henderson A. Interaction Analysis: Foundations and Practice. Journal of the Learning Sciences. 1995;4(1):39-103.

44. Ranerup A, Hallberg I, Bengtsson U, Kjellgren K. Mastery and Autonomy in Medication With a Mobile Self-Report System-A Project in Action: Adjunct Proceedings of the Seventh International Conference on Persuasive Technology; June 6-8, 2012; Linköping, Sweden: Linköping University Electronic Press; 2012.

45. Mancia G, Fagard R, Narkiewicz K, et al; Task Force Members. 2013 ESH/ESC Guidelines for the management of arterial hypertension: the Task Force for the management of arterial hypertension of the European Society of Hypertension (ESH) and of the European Society of Cardiology (ESC). J Hypertens. 2013;31(7):1281-1357.

46. Baguet JP. Out-of-office blood pressure: from measurement to control. Integr Blood Press Control. 2012;5:27-34.

47. Snyder CF, Aaronson NK, Choucair AK, et al. Implementing patientreported outcomes assessment in clinical practice: a review of the options and considerations. Qual Life Res. 2012;21(8):1305-1314.
48. Krishna S, Boren SA, Balas EA. Healthcare via cell phones: a systematic review. Telemed J E Health. 2009;15(3):231-240.

49. Kronish IM, Ye S. Adherence to cardiovascular medications: lessons learned and future directions. Prog Cardiovasc Dis. 2013;55(6): 590-600.

50. Lupton D. Quantifying the body: monitoring and measuring health in the age of mHealth technologies. Crit Public Health. 2013;23(4):393-403.

51. Go AS, Bauman M, King SM, et al. An Effective Approach to High Blood Pressure Control: A Science Advisory From the American Heart Association, the American College of Cardiology, and the Centers for Disease Control and Prevention. Hypertension. Epub November 15, 2013.

52. McGillicuddy JW, Gregoski MJ, Weiland AK, et al. Mobile health medication adherence and blood pressure control in renal transplant recipients: proof-of-concept randomized controlled trial. JMIR Res Protoc. 2013;2(2):e32.

53. Kiselev AR, Gridnev VI, Shvartz VA, Posnenkova OM, Dovgalevsky PY. Active ambulatory care management supported by short message services and mobile phone technology in patients with arterial hypertension. J Am Soc Hypertens. 2012;6(5):346-355.

54. Rhee H, Allen J, Mammen J, Swift M. Mobile phone-based asthma self-management aid for adolescents (mASMAA): a feasibility study. Patient Prefer Adherence. 2014;8:63-72.

55. Pearson TA, Palaniappan LP, Artinian NT, et al; American Heart Association Council on Epidemiology and Prevention. American Heart Association Guide for Improving Cardiovascular Health at the Community Level, 2013 Update: a scientific statement for public health practitioners, healthcare providers, and health policy makers. Circulation. 2013;127(16):1730-1753.
Integrated Blood Pressure Control

\section{Publish your work in this journal}

Integrated Blood Pressure Control is an international, peer-reviewed open-access journal focusing on the integrated approach to managing hypertension and risk reduction. Treating the patient and comorbidities together with diet and lifestyle modification and optimizing healthcare resources through a multidisciplinary team approach constitute key

\section{Dovepress}

features of the journal. This journal is indexed on American Chemical Society's Chemical Abstracts Service (CAS). The manuscript management system is completely online and includes a very quick and fair peerreview system, which is all easy to use. Visit http://www.dovepress.com/ testimonials.php to read real quotes from published authors. 